\title{
OPERATIONAL ERRORS IN AIR TRAFFIC
}

\section{BLĘDY OPERACYJNE W RUCHU LOTNICZYM}

\author{
Wojciech Chmura $^{1}$, Marek Malarski ${ }^{2}$ \\ (1) Polish Air Navigation Services Agency \\ (2) Warsaw University of Technology, Faculty of Transport \\ e-mails: (1)chmura.w@wp.pl, (2)mma@it.pw.edu.pl
}

\begin{abstract}
The obligatory value representing the allowable number of events in air traffic (in particular accidents), calculated upon historical data known as Target Level of Safety - TLS, is at present valid only for accidents and equals $1,55^{*} 10^{-8}$ an accident per one flight hour. This value, unless the previously calculated TLS, would be reliable and this equation itself might be useful to monitor the current level of safety (CLS) by putting into it the current performance characteristics of a staff.
\end{abstract}

Keywords: air traffic control, operational errors

Streszczenie: Obowiązujący poziom bezpieczeństwa w ruchu lotniczym wyznaczony został na podstawie danych historycznych. Wartość granicznego poziomu bezpieczeństwa - TLS określono dla wypadków lotniczych na poziomie $1,55^{*} 10^{-8}$ wypadku na 1 godzinę lotu. Aktualny poziom bezpieczeństwa CLS musi być monitorowany i utrzymywany poniżej wartości granicznej TLS.

Słowa kluczowe: kontrola ruchu lotniczego, błędy operacyjne 


\section{OPERATIONAL ERRORS IN AIR TRAFFIC}

\section{Introduction}

Operational Errors (OEs) which mean the particular mistakes made by highly trained operator such as pilot, air traffic controller are the main cause of accidents and incidents in air traffic. OEs are influenced by many 'internal', 'external' and other factors. Internal factors result directly from man's nature (ability to aquire the knowledge, experience, personal problems, mental fatigue, etc.). External factors appear in sourrounding work environment (weather, time of a day, atmosphere at work place, etc). According to [2] the probability of controllr to make a mistake at work is a result of two causes: lack of an situational awareness and too high workload. These in turn, as said before, depend on 'internal' and 'external' factors and additionally on the kind of air traffic control service (area, approach, tower), density and complexity of traffic and of course on stress.

All member states gathered in an world aviation community are obliged to comply with many requirements, including the most important safety related. European Organization for Safety of Air Navigation (Eurocontrol) has established a numeric value called TLS which stands for target level of safety. It is used to ensure that air traffic control service provided by air navigation service provider is safe. In other words, this number (TLS) represents the maximum rate of event in air traffic to happen which is allowable in particular time period or for some number of air operations. Not only are procedures and equipment a part of an air traffic control system but also human who is also obliged to meet the TLS' requirements. For the time being TLS has been calculated only for accidents.

\section{Human errors}

Technical equipment, procedures and human operators are the three fundamental parts of which an air traffic control system consists. Technical failures have usually a simple cause and we are able to eliminate them efficiently by i.e. redundancy of critical circuits and elements or by using more advanced and dependable solutions and technologies. The same applies to procedures which can be easily transformed or re-write. Unfortunately, for the time being we are unable to exclude the human 
operator out of the air traffic control system in order to eliminate human errors. Still, the way the human performance is highly influenced by many agents like stress, mood, medical conditions, distraction, time of a day, weather, workload, atmosphere at workplace etc.

Operator's errors may be neglegible and may cause the work quality to deteriorate or they may be serious and as a result pose a danger to safe air traffic control service. Such mistakes, made by an air traffic controller, are called operational errors and intensity of them to happen is one of a system safety measures. FAA - Federal Aviation Administration (USA) defines an operational error as an event in air traffic which results in separation minima infringement between two aircraft or between aircraft and terrain or obstacle, or an aircraft landed on/departed from closed runway after being given clearance to do so by air traffic control services. These all events are considered to be a serious ones and are classified by Eurocontrol as 'serious incidents' or 'incidents'. It should be noticed that not every single operational error pose the same danger. In one case, despite the minimum separation being infringed, two aircraft are still afar enough but in another case they hardly colide. These two examples describe an operational error defined above.

\section{Factors influencing an error}

An accident or incident in air traffic is usually caused by chain of mishaps like human error, incorrect procedures, technical failure of an equipment, meteorological conditions etc. In this article the focus is only on human error. There were many observation and research which led to an answer what conduces to highly trained operator makes a tragic operational mistake. Two crucial factors are responsible for this: situational awareness and workload. The correctiveness of issued clearances and instructions depends on them. Situational awareness makes it possible for controller to focus on traffic, to manage the situation and to predict how it developes. Lack of awareness results in controller not to predict such a pace of events which leads to potential colision of aircraft controlled or he/she noticed it too late to take any action. Figure No 1. depicts many different factors that influence workload and situational awareness. 


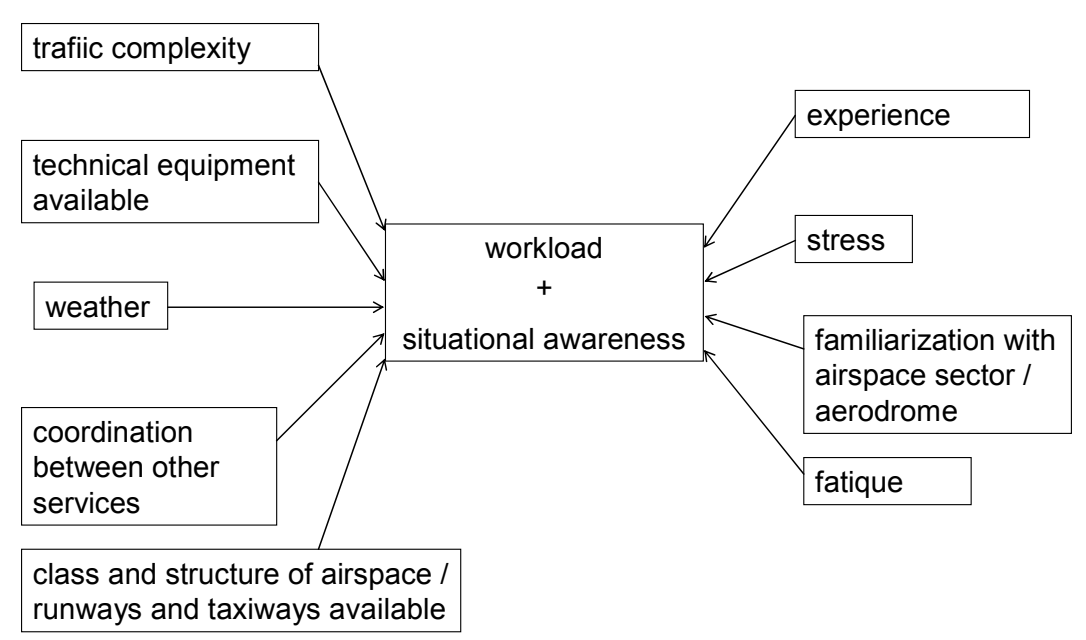

Figure 1. Factors influences to workload and situational awareness.

\section{Workload and jetlag}

Significant growth of air traffic all over the world forces air navigation service providers to create work methods which make it possible for controllers to manage it safely without the continuous need to arrange new solutions for every singular traffic situation. In vast majority of cases the work of an air traffic controller follows some repetitive patterns. This applies not only to controlers but also to pilots. Repetitiveness of some actions makes it possible to handle even a heavy traffic without difficulties. However, when unexpected things happen it requires from pilot/controller to take some actions which are in accordance with law but also are an improvisation. This on one hand makes pilot's/controller's work so fascinating but on the other it contributes to increasing of the probability of an error. Usually, in such situation, controller focuses all attention on solving this problem distracting him/herself from the rest of traffic which can easily turn into next dangerous situation. However, specialists highlight the side effect of handling traffic in repetitive and schematic manner. This aims on one hand at workload to be lowered but may also contribute to jetlag which results in alertness and conflict perception to deteriorate, on the other. It seemed to be obvious that reducing the workload must lead to the number of mistakes to decrease, but it is misleading. It turns out that despite introduction of the repetitive work patterns which lower the workload the situational awareness is often deteriorated. It just happens because of jetlag. Every controller identifies the same traffic situation in different way. It is 
because the diffetrent proficiency levels, experience, time of a day, familiarization of an airspace sector, health condition, etc. Therefore, it may be said that workload is a subjective sensation and depends on particular person. Because of fact that it seemed to be impossible to assess workload in direct and unambiguous way scientists decided to examine human brain and heart. These two organs react to stress in very specific and visibile way. Drekker [1] in course of many medical experiments on controllers proved organizm's physical reaction to workload is the same (pulse rate increases, blood preasure rate increases, electroencephalographic record of brain waves changes). Reaction of organizm is reliable enough to predict the workload overcomes controller's perception. Unfortunately - he said - to perform such measurements on a daily manner at real workplace was impossible. Prof. Drekker firmly claims that statement as such 'maximum workload' does not exist. It usually depends on too many agents (rest time, personal problems, experience and training rate, weather, time of a day, atmosphere at workplace, etc.) to estimate it in simple way. Therefore, workload can not determine the controller makes an error.

\section{Situational awareness and traffic complexity}

Increase in air traffic may contribute to its complexity. There is also another essential factor which impacts the traffic complexity: flight rules (IFR instrument flight rules/ VFR - visual flight rules) and related to this aircraft's performace. There is strong correlation between aircraft's performance and method of separation and also unexpected and dangerous events. Analysis [2] of 85 OEs made by air traffic controllers between 1992 and 1995 in one of the area control sectors in USA proves that influence of traffic cimplexity on workload was the main cause of OEs. The vast majority of OEs are usually being made neither at very heavy nor at very low traffic density but at an average one. It happens because at the high level of traffic controller is very alert, focuses on traffic and manages it. When traffic is low and not complex, the probability of an event is quite rare but of course an event can happen (compare the accident over Ueberlingen). Average traffic level in terms of density and complexity gives to the controller not only some rest after handling heavy traffic but also the sense of managing the situation. At that time distracted attention, relax and false feling that everything is under control are the common causes of an event. Therefore, change from peak periods to low traffic is one of the most dangerous parts of a shift. [2] derives the next interesting conclusion. It proved that controller's awareness about potential conflict was higher at heavy traffic. However, the more severe was effect of an event the less 
controller was aware of it. OEs happen because controllers let the traffic situation to develope and transform into a dangerous one in such way that either controllers are not aware of conflict or they find it dangerous too late. Mica and Rodgers in [4] present the experiment on a group of air traffic controllers aiming at examination of situational awareness. Participants were asked to watch a replay of an incidents/accidents caused by $\mathrm{OE}$ recorded by air traffic control radar system. Then the presentation was displayed again but it was stopped in different moments and the screen went blank. During the interruptions in display controllers were asked to point out the exact position of all aircraft known to them at the moment, their current altitude, ground speed, heading, etc. As a result of the experiment participants proved not to be able to do this task fully. They often failed to indicate the present performance, correct location or even the existence of some aircraft. This test was made in a 'pure' lab environment which is deprived of some tools which help the controller to be kept in picture all the time i.e. flight strips. However, the test confirms that conflict detection is heavily impared when controller has no full awareness of what is going on in his/her airspace of responsibility at the moment.

\section{Target Level of Safety and $\mathrm{OE}$ indicators}

European Organization for Safety of Air Navigation (Eurocontrol) accepted the numeric value of $1,55^{*} 10^{-8}$ accident per one flight hour as a target frequency of and accident - because of direct contribution of Air Traffic Management - ATC - to happen. It was called TLS which stands for Target Level of Safety. Present TLS was caculated on the basis of historical data as a rate of accidents to total number of flight hours flown by all 'schedule' flight in 20 year time period. Despite this value being now in force in many legal systems all over Europe, the reliability of its calculation was thrown into doubts. The value representing maximum allowable number of accidents must be justified and must depend on real capabilities of an ATM system which consists not only of equipment and procedures but of humans and his/her weaknesses after all. This vital restriant of a system is not included in present 'method'.

In 1999 in USA the OE rate among the area controllers was 1,41 OE per 100000 operations and was as twice higher as this among approach controller (0,65 OE per 100000 operations). What is more, it was noticed that area controler's rate had a tendency to increase while approach controller's rate was levelled off. In turn, some european countries demonstrated their doubts toward 1,55 TLS and has even announced they are unable to ensure the present TLS in some parts of their airspace because 
of the traffic density. This all gives the evidence to calculate the future TLS separately for area and approach/tower air traffic control services just because of specific traffic patterns and work schemes.

\section{The proposed method of re-calculation of the present TLS}

As it was said before, it is very difficult, on the basis of either workload or awareness criteria, to calculate the probability of a controller to make a mistake. If so, one may try to use a more reliable methods. There are some mathematical equations, specifically these in theory of stochastic processes, which can give dependability of an 'object in question' as a result. This 'dependability' may not be only used for technical equipment but also for human operator. In this case, it represents capability of an operator to do some activities on the error-free manner which can be interpreted as TLS (vast majority of accidents and incidents in air traffic are caused by errorenous action taken by 'human operator' - up to $80 \%$ ).

For this article 48 events which took place in Poland for years 2004-2006 were analised. 21 out of them has been rule out because of lack of correlation with air traffic control blame. 20 out of the rest 27 followed the same pattern depicted below.

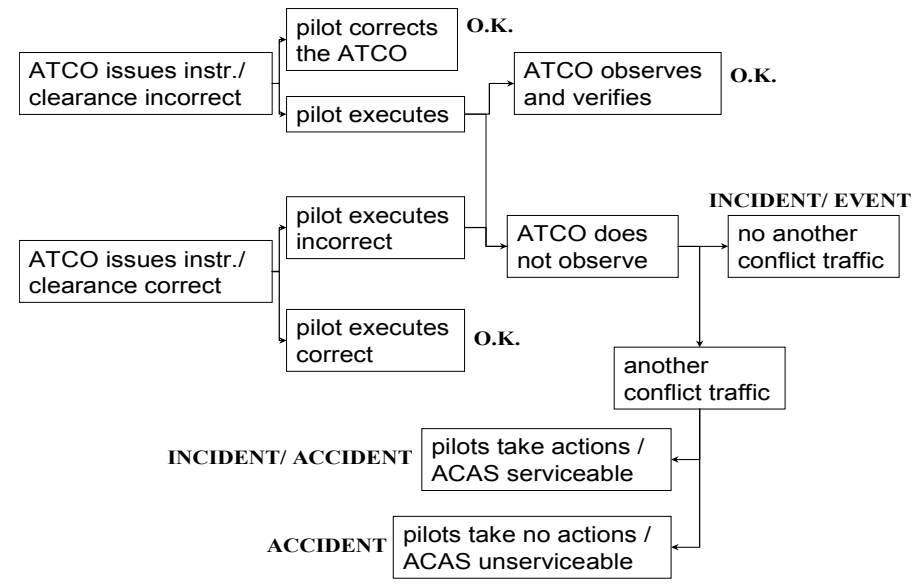

Figure 2. Incident / accident scheme

Unfortunately, this pattern is useless to calculate transition densities because it does not consist of temporary states. This is the problem for the future work to face on how to transpose this scheme to dependability-based one. For the time being however, the desired $\lambda$ may be calculated in the 'shortcut' way which omits the lacking dependability scheme. Let us solve the Kolmogorov equation in oposite direction. Let us assume we know $R(t)$ value and let us transform this equation to calculate the $\lambda$. In order to do so 
$R(t)$ must be known. In the course of analysis 3 intensities of incidents for 2004, 2005 and 2006 were calculated upon the data given. The number of operations, number of incidents happened and incidents' densities $R(t)$ are shown on the figure below. This method lets calculate the $\lambda$. It should be noticed that it is calculated for the incident scheme. Over the last years there was no accident caused by air traffic control services. In order to calculate the TLS for accidents it is needed to have the lacking part of the equation representing the transition from state which ends with incident to the state which leads to an accident. For the time being it is undergoing work.

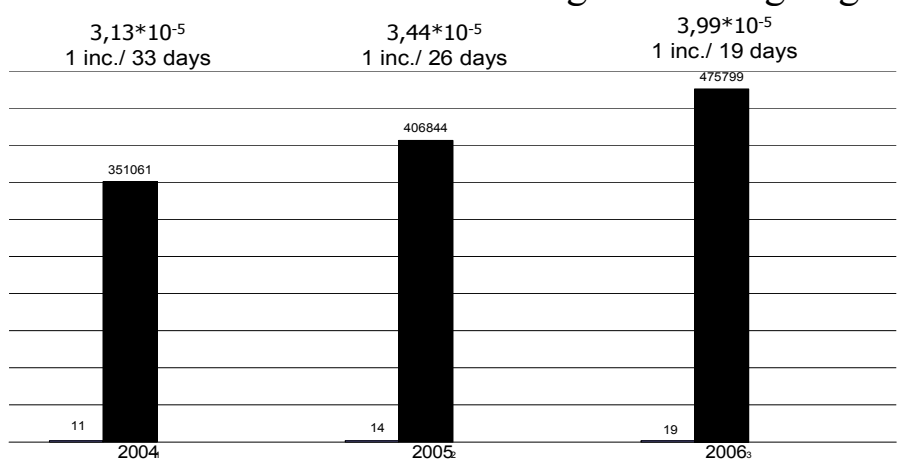

Figure 3. Statistical of ATM events in Poland in 2004-2006.

Having calculated the TLS for incidents and for accidents we have the criteria for tolerability of the errors made by controllers at the same time. It is an easy tool to monitor the current level of safety within air navigation service provider's agency.

\section{References}

1. Drekker S.: Workload a strange concept, Human factors and aviation safety. Lund University of Sweden: Hindsight Magazine2007.

2. Gosling G. D.: Analysis of the factors affecting the occurrence and severity of air traffic control operational errors, University of California, Institute of Transportation Studies 2005

3. Malarski M.: Safety of operation of man - Complex transport systems scheme (in polish), AM Szczecin, Zeszyty Naukowe 2006.

4. Mica E., Rodgers M. D.: Distribution of attention, situation awareness and workload in a passive air traffic control task: Implication of operational errors and automation. Washington D.C.: Federal Aviation Administration, Office of Aviation Medicine, Report No. DOT/FAA/AM-97/13, 1997.

5. Ruitenberg B.: Workload versus boredom, Front line report. Amsterdam, Netherlands, Schiphol Airport,. Hindsight Magazine 2007. 